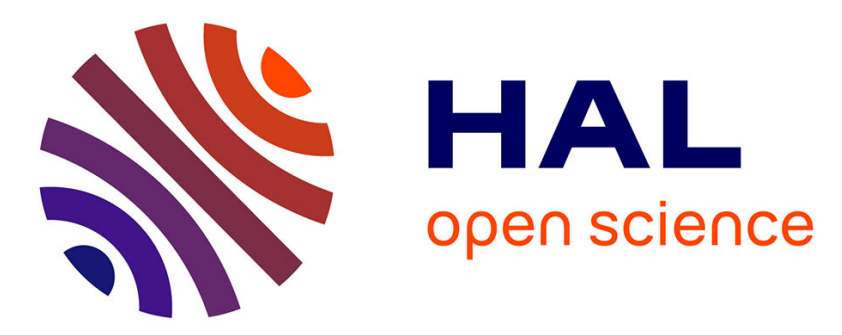

\title{
Photoluminescence of Eu2+-Doped Strontium Cyanamide: A Novel Host Lattice for Eu2+
}

Shuanglong Yuan, Yunxia Yang, François Cheviré, Franck Tessier, Xianghua Zhang, Guorong Chenz

\section{To cite this version:}

Shuanglong Yuan, Yunxia Yang, François Cheviré, Franck Tessier, Xianghua Zhang, et al.. Photoluminescence of Eu2+-Doped Strontium Cyanamide: A Novel Host Lattice for Eu2+. Journal of the American Ceramic Society, 2010, 93 (10), pp.3052-3055. 10.1111/j.1551-2916.2010.04025.x . hal$00608655 \mathrm{v} 1$

\section{HAL Id: hal-00608655 https://hal.science/hal-00608655v1}

Submitted on 16 Dec 2015 (v1), last revised 17 Nov 2020 (v2)

HAL is a multi-disciplinary open access archive for the deposit and dissemination of scientific research documents, whether they are published or not. The documents may come from teaching and research institutions in France or abroad, or from public or private research centers.
L'archive ouverte pluridisciplinaire HAL, est destinée au dépôt et à la diffusion de documents scientifiques de niveau recherche, publiés ou non, émanant des établissements d'enseignement et de recherche français ou étrangers, des laboratoires publics ou privés. 


\title{
Photoluminescence of $\mathrm{Eu}^{2+}$-doped strontium cyanamide: A novel host lattice for $\mathrm{Eu}^{2+}$
}

Shuanglong Yuan, ${ }^{1,2}, *$ Yunxia Yang, ${ }^{1}$ François Cheviré, ${ }^{2}$ Franck Tessier,2 Xianghua Zhang, ${ }^{1,2}$ and Guorong Chenz ${ }^{1}$

${ }^{1}$ Key Laboratory for Ultrafine Materials of Ministry of Education, School of Materials Science and Engineering, East China University of Science and Technology, Shanghai 200237, China

${ }^{2}$ UMR CNRS 6226 Sciences Chimiques de Rennes, équipe Verres et Céramiques, Université de Rennes 1, 35042 Rennes cedex, France

*e-mail: shuanglong@ecust.edu.cn

\begin{abstract}
$\mathrm{Eu}^{2+}$-doped $\mathrm{SrCN}_{2}$ with different $\mathrm{Eu}^{2+}$ contents were prepared by a high-temperature solidstate reaction under $\mathrm{NH}_{3}$ atmosphere. $\mathrm{SrCN}_{2}$ has an energy gap of $4.56 \mathrm{eV}$ by the reflection spectra. The photoluminescence spectra of $\mathrm{SrCN}_{2}: \mathrm{Eu}^{2+}$ at different temperatures were measured. The results show that $\mathrm{Eu}^{2+}$-doped $\mathrm{SrCN}_{2}$ shows a broad band emission with a peak at $610 \mathrm{~nm}$ when it is excited by $350-520 \mathrm{~nm}$ at $77 \mathrm{~K}$. With the temperature increasing, the emission intensity decreases remarkably, indicating that $\mathrm{Eu}^{2+}$-doped $\mathrm{SrCN}_{2}$ has a low quenching temperature.
\end{abstract}

\section{Introduction}

The emission and absorption spectra of $\mathrm{Eu}^{2+}$ usually consist of broad bands due to electronic transitions between the ${ }^{8} \mathrm{~S}_{7 / 2}\left(4 f^{7}\right)$ ground state and the crystal field components of the $4 f^{6} 5 d$ excited state configuration. Because the involved $5 d$ orbitals are external, the position of these 
energy levels and consequently the wavelengths of excitation and emission bands strongly depend on the host matrix [1]. With the increasing covalency between $\mathrm{Eu}^{2+}$ and ligands, the emission of $\mathrm{Eu}^{2+}$ shifts to longer wavelength [2]. For example, the $\mathrm{Eu}^{2+}$ emits from near violet to blue in halide hosts due to highly electronegative halogen ions, but at longer wavelengths in nitrides due to lower electronegative $\mathrm{N}^{3-}[2]$.

$\mathrm{SrCN}_{2}$ belongs to the hexagonal Pnma space group (no. 62) with $a=512.41 \AA, b=53.96 \AA$, and $\mathrm{c}=55.39 \AA$. In the $\mathrm{SrCN}_{2}$ host crystal, $\left[\mathrm{CN}_{2}\right]^{2-}$ anions in two orientations built up layers parallel to the a-c plane of the unit cell. The $\mathrm{Sr}^{2+}$ ions also belong to these layers, forming distorted octahedra around the anions. Distorted nitrogen octahedra centered by $\mathrm{Sr}^{2+}$ ions are connected via sharing corners and by NCN bridges [3].

$\mathrm{As} \mathrm{Sr}^{2+}$ ions connect to $\mathrm{N}^{3-}$, it is reasonable to expect that $\mathrm{SrCN}_{2}$ would be used as host lattice for divalent lanthanides. However, reported work in this respect is rare. In the present work, $\mathrm{Eu}^{2+}$-doped $\mathrm{SrCN}_{2}$ were prepared and its optical properties were investigated in detail.

\section{Experiments Procedures}

Powder samples with general formula $\operatorname{Sr}_{(1-\mathrm{x})} \mathrm{CN}_{2}: \mathrm{Eu}_{\mathrm{x}}(\mathrm{x}=0.01,0.02,0.03,0.04$, and 0.06) were prepared by using $\mathrm{SrCO}_{3}, \mathrm{Eu}_{2} \mathrm{O}_{3}$, and active carbon (CARBIO $12 \mathrm{SA}$-ref: C1220 G 90) as raw materials following a process inspired from the literature [4]. The mixture of europium oxide and the strontium carbonate was placed at the end of a graphite boat, while the active carbon was put in the upcoming flowing gas at the other end. The mixture was then fired at $1223 \mathrm{~K}$ under $\mathrm{NH}_{3}$ atmosphere for $6 \mathrm{~h}$ in a tubular furnace.

The synthesized powder samples were analyzed by X-ray diffraction (XRD) (Philips PW3710, PANalytical B.V., Almelo, the Netherlands) at room temperature using $\mathrm{CuK \alpha}$ radiation $(\lambda=1.54056 \AA)$. A step size of $0.02^{\circ}(2 \theta)$ was used with a scan speed of $2^{\circ} / \mathrm{min}$. The nitrogen and oxygen contents were determined with an LECO TC-600 analyzer (LECO 
Corporation, St. Joseph,MI) using the inert gas fusion method. The measurements of photoluminescence (PL) and PL excitation spectra between 77 and $293 \mathrm{~K}$ were carried out by a Fluorolog-3 spectrofluorometer (Jobin Yvon Inc./specx, HORIBA Jobin Yvon Inc., Edison, $\mathrm{NJ})$ equipped with a VNF-100 liquid nitrogen cryostat controlled by a cryogenic temperature controller model 32, and the excitation light resource is a $450 \mathrm{~W}$ Xe lamp. Diffuse reflectance spectra in the range of $200-700 \mathrm{~nm}$ were collected using a Varian Cary $100 \mathrm{UV}-\mathrm{Vis}$ spectrophotometer (Varian Inc., Fontaine, Grenoble, France) equipped with an integrating sphere Labsphere (DRC-CA-30) with $70 \mathrm{~mm}$ diameter.

\section{Results and Discussion}

\section{(1) Phase Characterization}

The XRD patterns of the series of powder samples $\operatorname{Sr}\left({ }_{1-\mathrm{x}}\right) \mathrm{CN}_{2}: \mathrm{Eu}_{\mathrm{x}}(\mathrm{x}=0.01,0.02,0.03,0.04$, and 0.06) are displayed in Fig. 1. The results show that all the products are of a single phase of $\mathrm{SrCN}_{2}$, in good agreement with the JCPDS 82-0988 file. However, with the increasing $\mathrm{Eu}^{2+}$ content, the diffraction peaks shift slightly to a lower d-value. This is most likely due to the partial substitution of $\mathrm{Sr}^{2+}$ by $\mathrm{Eu}^{2+}$, which has the lower ionic radius $(0.107 \mathrm{~nm})$ than $\mathrm{Sr}^{2+}$ $(0.112 \mathrm{~nm})$.

\section{(2) The Reflection Spectra}

The diffuse reflection spectra of $\mathrm{SrCN}_{2}$ :Eu samples are gathered in Fig. 2. Both undoped and $\mathrm{Eu}^{2+}$-doped samples show a remarkable drop in reflection in the UV range around $280 \mathrm{~nm}$, corresponding to the valence-to-conduction band transitions of the $\mathrm{SrCN}_{2}$ host lattice. The intense reflection in the visible spectral range is in agreement with the observed white daylight color for undoped $\mathrm{SrCN}_{2}$. In order to better localize the thresholds for host lattice absorption and the absorption by $\mathrm{Eu}^{2+}$, the absorption spectra $\mathrm{F}(\mathrm{R})$ were obtained (inset) from the diffuse reflection spectra by using the Kubelka-Munk function as follows [5]: 


$$
F(R)=(1-R)^{2} / 2 R=K / S
$$

where $\mathrm{R}, \mathrm{K}$, and $\mathrm{S}$ are the reflectivity, the absorption coefficient, and the scattering coefficient, respectively. The value of the optical band gap is calculated to be about $4.56 \mathrm{eV}$. For the samples of high $\mathrm{Eu}^{2+}$ concentration, two broad absorption bands can also be seen in the wavelength ranges of $320-500$ and $280-320 \mathrm{~nm}$, respectively. Both of them can be attributed to the $4 f-5 d$ absorption of $\mathrm{Eu}^{2+}$ ions, compared with that of undoped $\mathrm{SrCN}_{2}$. As expected, their intensities increase with the increasing $\mathrm{Eu}^{2+}$ concentrations. In contrast to the undoped samples with the white daylight color, $\mathrm{Sr}_{1-\mathrm{x}} \mathrm{CN}_{2}$ :Eu $\mathrm{E}_{\mathrm{x}}$ shows light yellow to bright yellow colors, varying with the $\mathrm{Eu}^{2+}$ concentration $(0<\mathrm{x} \leq 0.06)$ due to a strong absorption in the visible range of $380-500 \mathrm{~nm}$.

\section{(3) The PL Characteristics at Low Temperature}

The PL spectra of $\mathrm{SrCN}_{2}: \mathrm{Eu}_{0.02}$ at $77 \mathrm{~K}$ are presented in Fig. 3. With different excitation wavelengths at 396 and $491 \mathrm{~nm}$, emission spectra show the similar broad orangish-red emission with a maximum at about $610 \mathrm{~nm}\left(16393 \mathrm{~cm}^{-1}\right)$ and full-width at half maximum about $82 \mathrm{~nm}\left(\Gamma=2163 \mathrm{~cm}^{-1}\right)$. This broad emission band can be assigned to the $4 f^{6} 5 d^{1}-4 f^{7}$ transition of $\mathrm{Eu}^{2+}$. We do not observe the characteristic sharp emission peaks due to $\mathrm{Eu}^{3+}$ ions, which confirms existence of only $\mathrm{Eu}^{2+}$ ions in the present phosphors. Because only an exclusive transition is observed, we can deduce that all $\mathrm{Eu}^{2+}$ ions occupy identical sites. This is identical to the expectation because there is only one crystallographically distinct $\mathrm{Sr}^{2+}$ ion in $\mathrm{SrCN}_{2}$ host. The unusual long-wavelength and broad emission bands are due to the effect of the nitrogen-rich surrounding on $\mathrm{Eu}^{2+}$ ions in $\mathrm{SrCN}_{2}$, which caused the large ligand-field splitting of the $\mathrm{Eu}^{2+} 5 d$ levels, and then a larger nephelauxetic effect.

The excitation spectrum at $77 \mathrm{~K}$ monitored at an emission wavelength of $610 \mathrm{~nm}$ is also shown in Fig. 5. It consists of a broad band with several subbands, which are due to the parity 
allowed $4 f^{7}\left({ }^{8} \mathrm{~S}_{7 / 2}\right)-4 f^{6} 5 d$ transitions of $\mathrm{Eu}^{2+}$ ions. These subbands structures, peaked at 335, 396, 449, 456, and $491 \mathrm{~nm}$, are assigned to the crystal field splitting of the $5 d$ level of $\mathrm{Eu}^{2+}$ ions. The excited $5 d$ levels are not shielded from the ligand field, giving rise to a marked splitting of the excited levels. The symmetry of the anion coordination polyhedron around the emission centers determines the number of the splitting level. Dorenbos [6] has made a clear correlation between the splitting and the coordination polyhedron, revealing that the crystal field splitting tends to be the largest for octahedral coordination followed by cubic, dodecahedral, and it is the smallest for tricapped trigonal prism (3ctp) and cuboctahedron coordination. In the $\mathrm{SrCN}_{2}: \mathrm{Eu}^{2+}$ crystal, $\mathrm{Sr}^{2+}$ ions coordinating with six $\mathrm{N}^{3-}$ with different bond lengths form an asymmetric structure. Because the doped $\mathrm{Eu}^{2+}$ ions occupy asymmetric $\mathrm{Sr}^{2+}$ sites and are exposed to a strong ligand field due to the presence of highly covalent bonding of $\mathrm{Eu}-\mathrm{N}$, a large ligand-field splitting occurs to $\mathrm{Eu}^{2+}$ ions, resulting in their excitation band extending into visible region. According to the excitation spectrum, the crystal field splitting is estimated to be about $12019 \mathrm{~cm}^{-1}$, assuming no $5 d$ subbands to be positioned in the conduction band of the host lattice. A rough estimate of the Stokes shift determined by the maxima of the emission and excitation bands is $8859 \mathrm{~cm}^{-1}$, which is fairly large and attributed to the distortion of the excited state of $\mathrm{Eu}^{2+}$ due to $\mathrm{CN}_{2}{ }^{2-}$ anion groups surrounding the $\mathrm{Eu}^{2+}$ ions emission centers.

The broad excitation band and orangish-red emission mean that the $\mathrm{SrCN}_{2}$ should be a good host lattice for doping $\mathrm{Eu}^{2+}$, like $(\mathrm{Ca}, \mathrm{Sr}) \mathrm{S}$ and $\mathrm{Sr}_{2} \mathrm{Si}_{5} \mathrm{~N}_{8}$, which have been used as the red components of white light-emitting diodes illumination $[7,8]$. However, the emission of $\mathrm{SrCN}_{2}: \mathrm{Eu}^{2+}$ is strongly quenched with increasing temperatures and not observable at room temperature. The emission intensity dependence on the temperature using the excitation wavelength of 396 and $491 \mathrm{~nm}$ is depicted in Fig. 4. When it is excited at $396 \mathrm{~nm}$, the temperature at which the intensity is half of that at $77 \mathrm{~K}$ is about $\mathrm{T}_{1 / 2}=90 \mathrm{~K}$, and at $227 \mathrm{~K}$ the 
emission is completely quenched. These temperatures are slightly lower than those excited at $491 \mathrm{~nm}\left(\mathrm{~T}_{1 / 2}=92 \mathrm{~K}\right)$. Besides, the emission peaks slightly broaden and shift to the longer wavelength with the increasing temperature.

The luminescence behavior of $\mathrm{SrCN}_{2}: \mathrm{Eu}^{2+}$ is similar to those of $\mathrm{Ba}(\mathrm{SCN})_{2}: \mathrm{Eu}^{2+}$ and $\operatorname{Sr}(\mathrm{SCN})_{2}: \mathrm{Eu}^{2+}$. In $\mathrm{Sr}(\mathrm{SCN})_{2}: \mathrm{Eu}^{2+}$, it can be well explained by photoionization of the excited states in the conduction band of the host lattice $[9,10]$, that is, the lowest $5 d$ state is located at the level in the band gap of the host lattice slightly lower than the conduction band. After excitation, conventional $d \rightarrow f$ emission and/or nonradiative relaxation from an excitation state located in the conduction band may occur depending on the thermal population of the excitation state. However, this model seems unable to explain the thermal quenching behavior of $\mathrm{SrCN}_{2}: \mathrm{Eu}^{2+}$ in the present case. This is because upon $491 \mathrm{~nm}$ excitation on $\mathrm{SrCN}_{2}: \mathrm{Eu}^{2+}$, the excited electrons of $\mathrm{Eu}^{2+}$ ions most likely remained in the lower $5 d$ levels rather than moved to the higher levels due to large crystal splitting energy $\left(12019 \mathrm{~cm}^{-1}\right)$. Besides, the low quenching temperature is not due to a large displacement between the ground and excited state in the configuration coordinate diagram [11]. Therefore, we present a configurational coordinate diagram as shown in Fig. 5 to explain the temperature dependence of luminescence, as well as the red shift and broadening of emission with the increasing temperature occurring to $\mathrm{SrCN}_{2}: \mathrm{Eu}^{2+}$ phosphors. The lower and higher potential curves represent the total energy of the ground state of $4 f^{7}\left({ }^{8} S_{7 / 2}\right)$ and the excited state of $4 f^{6} 5 d$, respectively. The equilibrium positions of the two states are different from each other because of the spatial distribution of the electron orbitals. Generally, A $\rightarrow$ B1,B2 represents the absorption process and $\mathrm{C} 1 \rightarrow \mathrm{D} 1$ the emission [12]. However, with the increasing temperature, the excited electrons would depart to nonequilibrium positions of the excited state (e.g., $\mathrm{C} 2$ or $\mathrm{O}$, the crossing point between the excited state and the defect level). As a result, the emission shifts to the longer wavelength and its intensity decreases [13]. 
In general, the low quenching temperature originates from the crystal defect or the effect of activated ions with the host crystal. The best probability is from the crystal defect. In fact, in as-prepared samples, almost $1 \%$ molar oxygen remained as measured by an LECO analyzer, and they were most likely introduced in the preparation process from the raw materials $\mathrm{SrCO}_{3}$ and $\mathrm{Eu}_{2} \mathrm{O}_{3}$. The oxygen could be incorporated on the $\mathrm{N}$ site in $\mathrm{Eu}^{2+}$-doped $\mathrm{SrCN}_{2}$, forming the defect of $(\mathrm{ON})^{\bullet}$. To realize the charge compensation of $\mathrm{O}$ substitution on $\mathrm{N}$ sites, some cation vacancies such as $\left(V_{\mathrm{Sr}}\right)^{\prime \prime}$ have to be formed. Upon UV excitation of the host lattice, these defects may serve as carrier traps by capturing electrons or holes. It is reasonable to assume that $(\mathrm{ON}){ }^{\bullet}$ will capture electrons, while $\left(V_{\mathrm{Sr}}\right)^{\prime \prime}$ will capture holes. Hence, when $\mathrm{SrCN}_{2}: \mathrm{Eu}^{2+}$ is excited by UV light, the excited electrons could be captured by $(\mathrm{ON})^{\bullet}$, resulting in nonradiative transition. Therefore, it is essential to prepare oxygen-free samples, and thus the synthesis process should be investigated further.

\section{Conclusion}

Singe-phase $\mathrm{SrCN}_{2}: \mathrm{Eu}^{2+}$ powder samples were prepared by a high-temperature solid-state reaction under $\mathrm{NH}_{3}$ atmosphere. $\mathrm{SrCN}_{2}$ has an energy gap about $4.56 \mathrm{eV}$ obtained from its reflection spectrum. $\mathrm{Eu}^{2+}$-doped $\mathrm{SrCN}_{2}$ shows a broad band emission with a peak at $610 \mathrm{~nm}$ when it is excited by $350-520 \mathrm{~nm}$ at $77 \mathrm{~K}$. With the temperature increasing, the emission intensity decreases remarkably. When it is excited by $396 \mathrm{~nm}$, the temperature at which the intensity is half of that at $77 \mathrm{~K}$ is about $\mathrm{T}_{1 / 2}=90 \mathrm{~K}$, and at $227 \mathrm{~K}$ the emission is completely quenched; these temperatures are slightly lower than those excited by $491 \mathrm{~nm}\left(\mathrm{~T}_{1 / 2}=92 \mathrm{~K}\right)$. Besides, the emission peaks experience a slight red shift and become broader with the increasing temperature. These phenomena can be explained by the configurational coordinate diagram and could be attributed to the defect levels originated from the oxygen impurity in the host. 


\section{References}

[1] J. Liu, J. Sun, and C. Shi, Mater. Lett., 60(23) (2006) 2830-3.

[2] P. Dorenbos, J. Lumin., 91(3-4) (2000) 155-76.

[3] U. Berger and W. Schnick, J. Alloys Compd., 206(1-2) (1994) 179-84.

[4] Y. Hashimoto, M. Takahashi, S. Kikkawa, and F. Kanamaru, J. Solid State Chem., 114(2) (1995) 592-4.

[5] G. Kortum and G. Schreyer, Z. Naturforsch., 11A (1956), 1018-22.

[6] P. Dorenbos, J. Lumin., 104(4) (2003) 239-60.

[7] X. Piao, T. Horikawa, H. Hanzawa, and K. Machida, Appl. Phys. Lett., 88(16) (2006) $161908,3 p p$.

[8] Y. Hu, W. Zhuang, H. Ye, S. Zhang, Y. Fang, and X. Huang, J. Lumin., 111(3) (2005) $139-45$.

[9] C. Wickleder, J. Alloys Compd., 374(1-2) (2004) 10-3.

[10] C. Wickleder, Chem. Mater., 17(5) (2005) 1228-33.

[11] P. Dorrenbos, J. Phys. Condens. Matter, 17(50) (2005) 8103-11.

[12] K. Sakuma, N. Hirosaki, and R. J. Xie, J. Lumin., 126(2) (2006) 843-52.

[13] S. Shionoya and W. M. Yen, Phosphor Handbook, p. 36. CRC Press LLC, New York, 1998. 


\section{Figures}

Figure 1 : The X-ray diffraction spectra of $\mathrm{Sr}_{\left(1_{-} \mathrm{x}\right)} \mathrm{CN}_{2}: \mathrm{Eu}_{\mathrm{x}}{ }^{2+}$.

Figure 2 : The diffuse reflection and absorption spectra of $\operatorname{Sr}_{\left(1_{\_} \mathrm{x}\right)} \mathrm{CN}_{2}: \mathrm{Eu}_{\mathrm{x}}{ }^{2+}$.

Figure 3 : The emission and excitation spectra of $\mathrm{Sr}_{0.98} \mathrm{CN}_{2}: \mathrm{Eu}_{0.02}$ at $77 \mathrm{~K}$.

Figure 4 : (a) The emission spectra of $\mathrm{Sr}_{0.98} \mathrm{CN}_{2}: \mathrm{Eu}_{0.02}$ excited by $396 \mathrm{~nm}$ at different

temperatures. (b) The emission spectra of $\mathrm{Sr}_{0.98} \mathrm{CN}_{2}: \mathrm{Eu}_{0.02}$ excited by $491 \mathrm{~nm}$ at different temperatures.

Figure 5 : Schematic illustration of a configurational coordinate model. 
Figure 1

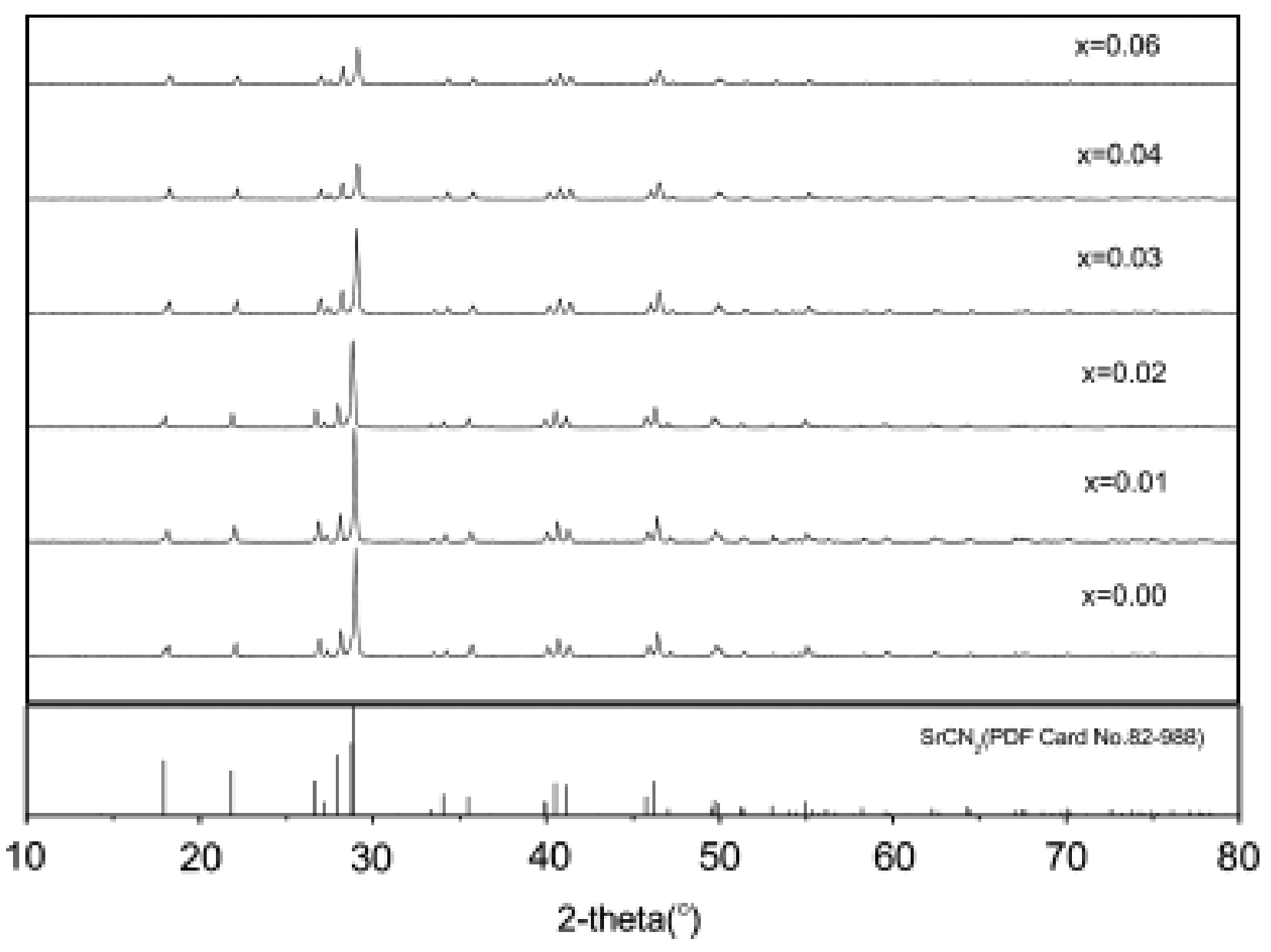


Figure 2

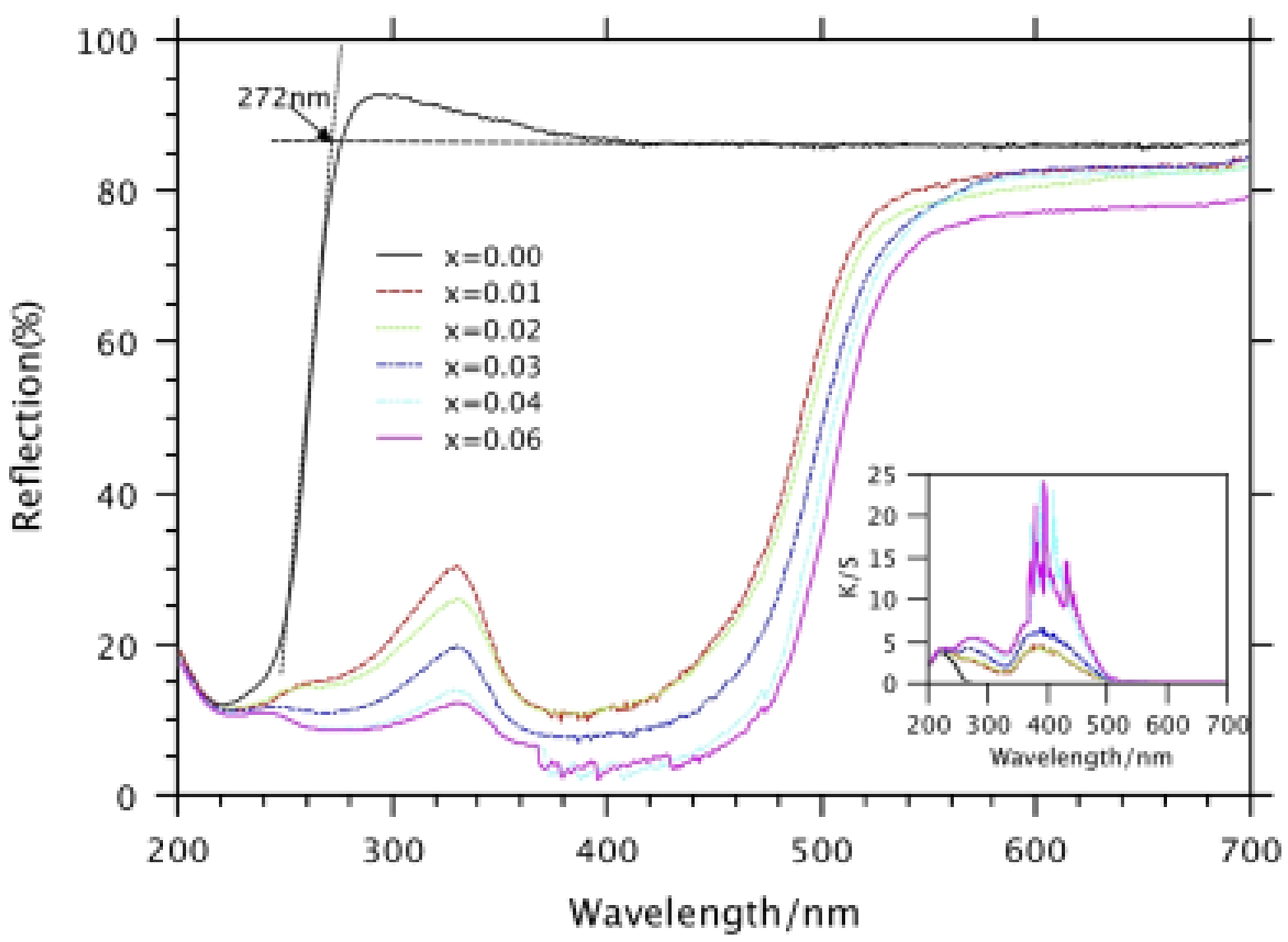


Figure 3

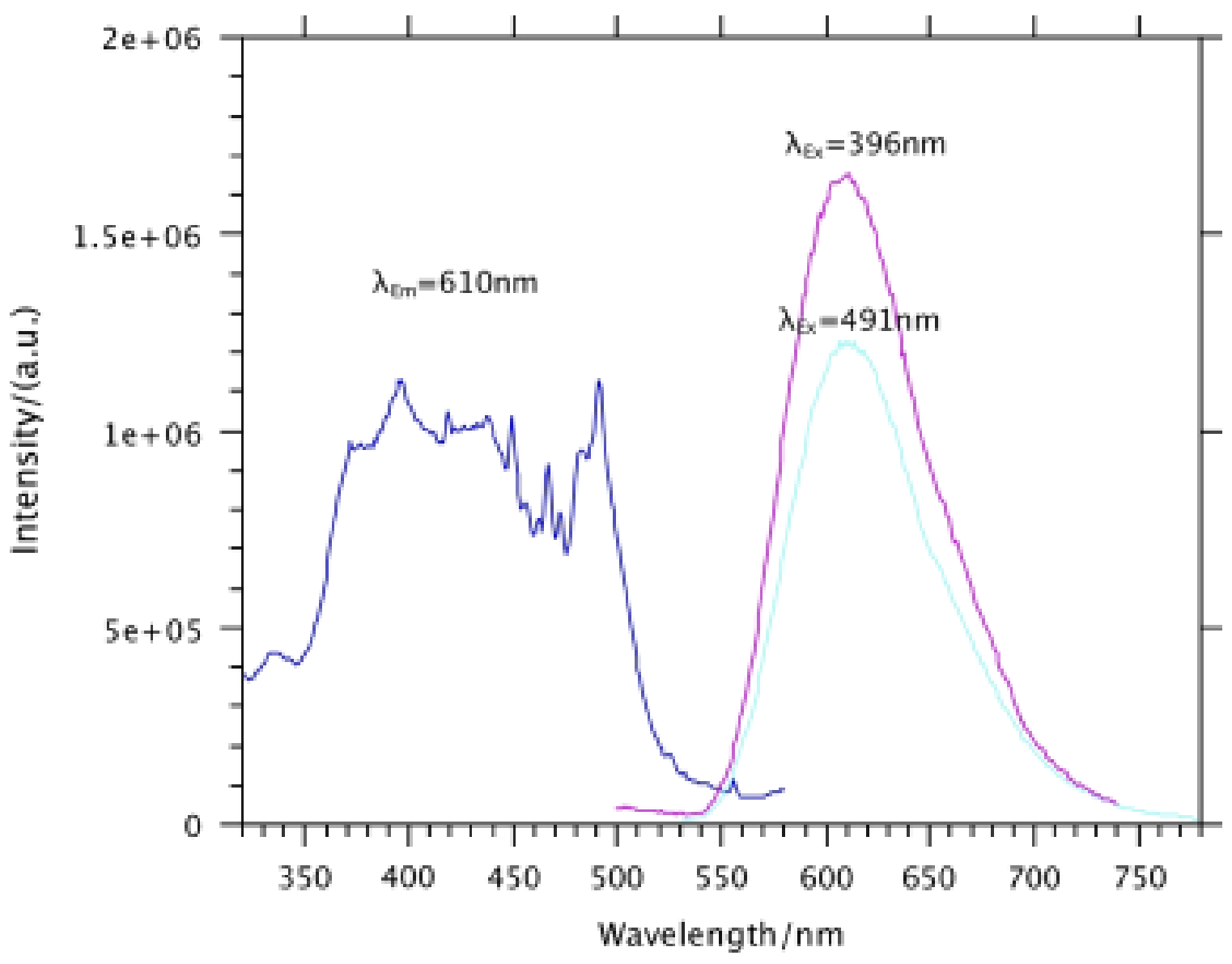


Figure 4
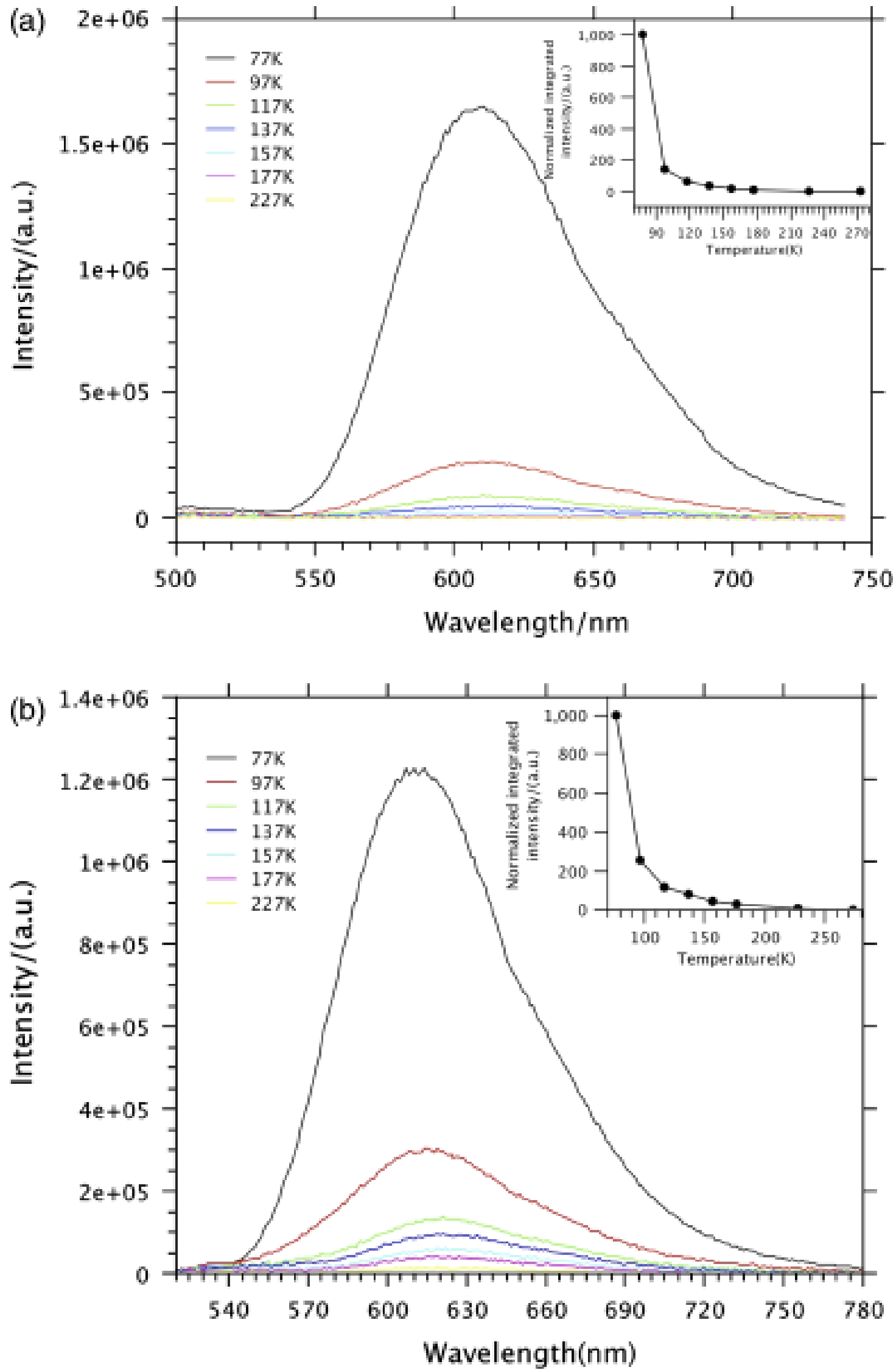
Figure 5

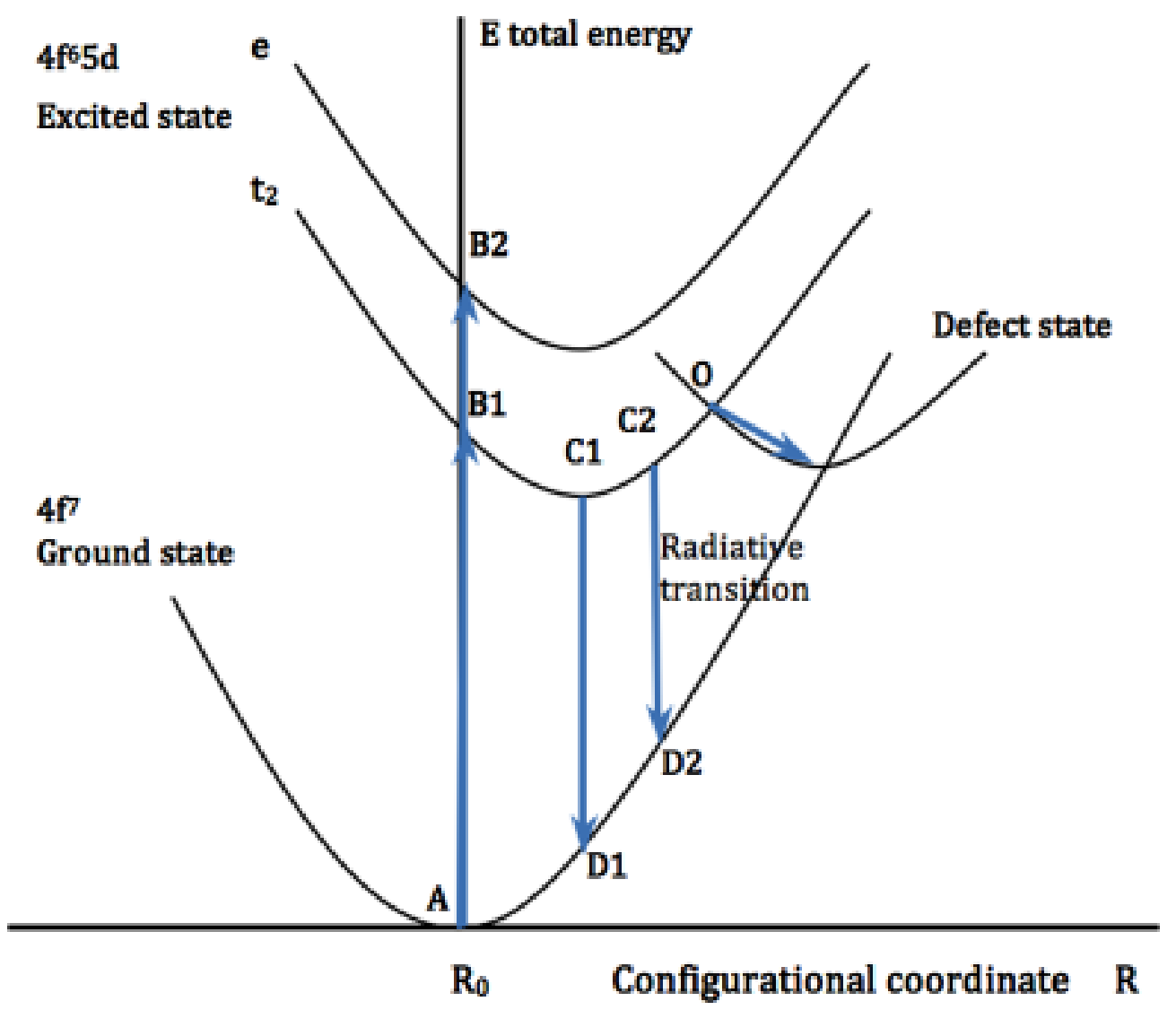

